\title{
Fluctuation of Serum TSH, FSH, Vitellogenin Level and Aassociated Ovarian Toxicity in Clarias batrachus (Linn.) Exposed to Pesticide
}

\author{
Prakriti Verma*, Rajnikant Kumar ${ }^{1}$ and Nishat Arfin ${ }^{1}$ \\ Post graduate Department of Zoology, Patna University, Patna (Bihar), India \\ ${ }^{1}$ Post Graduate Department of Biochemistry Patna University, Patna (Bihar), India
}

\begin{abstract}
A comprehensive study of serum Thyroid Stimulating Hormone (TSH), Follicle Stimulating Hormone (FSH) and Vitllogenin level of control and Rogor $(1 \mu \mathrm{l} / \mathrm{L}$ and $2.5 \mu \mathrm{l} / \mathrm{L})$ treated Clarias batrachus were done by ELISA. The present study revealed a wave of hormone imbalance and significant variations in the concentration of serum TSH, FSH and Vitellogenin level due to Rogor toxicity. The mean value of Thyroid Stimulating Hormone (TSH) level varied between $0.2 \pm 0.089 \mu \mathrm{IU}$ to $2.8 \pm 0.141 \mu \mathrm{lU}$ after Rogor exposure as compared to normal $2.255 \pm 0.187 \mu \mathrm{IU}$ value. Whereas, the mean value of Follicle Stimulating Hormone (FSH) fluctuate between $54.167 \pm 3.017 \mu \mathrm{IU}$ to $181.883 \pm 0.479 \mu \mathrm{IU}$ in comparison to normal value 144.5 $\pm 0.187 \mu \mathrm{IU}$. The mean value of vitellogenin ranges between $0.001 \pm 0.001 \mathrm{IU}$ to $2.86144 .5 \pm 2.94 \mathrm{IU}$ in comparison to normal $(2.24 \pm 3.31 \mathrm{IU})$ value. Light and Electron microscopy studies of ovarian tissue of Rogor treated fish have shown various treatment related abnormalities. Under Light microscopy ovarian tissue of normal $\mathrm{C}$. batrachus showed different stages of development in goocytes in the ovigerous lamellae extended from well developed germinal epithelium along with a few interstitial nutritive cells with distinct nucleus and nucleolus. However, Rogor exposure for 5 days, showed ruptured ovigerous lamellae, fusion of a number of young and maturing oocyte, shrinkage of nucleus and peripheral vacuolization which increased after 10 days and 15 Days exposure in both doses of Rogor (1 $\mu \mathrm{l} / \mathrm{L}$ and $2.5 \mu \mathrm{l} / \mathrm{L})$. Under Scanning electron microphotograph, three dimensional structures of ovarian cells also revealed grooves, pappilliations and protuberances on the surface of the ova which increased with dose and duration of exposure
\end{abstract}

Keywords: Clarias batrachus, Dimethoate, FSH, TSH, Vitellogenin, Ovary.

\section{Introduction}

Pesticide poisoning in fish is considered to be very serious as fish form major food resources for mankind affecting the consumer's health and may also adversely affect the yield of fish (Dubois, 1971). Toxicity tests with embryos and larvae are valuable for assessing potential impacts on growth, reproduction, and survival of organisms in polluted environments and are important tools for good environmental monitoring (Zagatto, 1999). Fishes occupying the highest tropic level of the water body, suffers the most due to the pesticides. Out of the different systems, reproductive system is one of the most important organ which gets affected to a great extent. Attempts have been made to study the deleterious effect of pesticides on ovary of fish (Dutta et al., 1994; Ramchandra, 2000; Verma and Nath 2003; Verma et al., 2004), thyroid gonad relationship (Kobayashi et al., 1998), follicle stimulating hormone (Okomassoun et al., 2002) and serum vitellogenin level (Montiverdiand et al., 2000; Nath and Maitra, 2001; Verma and Rani, 2013; Okumara et al., 2004). However, the scanning electron microscopic studies related to the histopathological effects of Rogor at sub cellular level in the ovary of fish and its correlation with Thyroid-gonad hormone level have not been dealt in much detail. The present investigation has been done with the aim to study the effect of Rogor on serum TSH, vitellogenin and $\mathrm{FSH}$ level in correlation with the histopathological 
and ultra structural changes in the ovary of air breathing fish Clarias batrachus (Linn.). The various hormonal and histopathological parameters were assessed during spawning season.

\section{Materials and Methods}

Live and healthy female species of Clarias batrachus (Linn.) average weight $60 \pm 10 \mathrm{gm}$ and $4.5 " \pm 2$ " lengths were procured from various wetland of North Bihar. The fishes were brought to the laboratory, disinfected with $0.1 \%$ $\mathrm{KMNO}_{4}$ solution and kept for acclimatization in the standard laboratory condition in Plexiglas aquaria and plastic pools. To maintain normal water temperature, cooler and exhaust were used around the aquarium. The aerated tap water was changed daily. After 48 hours, fishes were fed with pellets of wheat flour and egg @ $5 \%$ of their body weight. After, two weeks of properly acclimatization fishes were categorized into two groups. Group I - comprises normal and Group II - comprises for Rogor treated test fishes which were further subdivided into sub groups (6 fishes in each) according to the doses of pesticide. In the present investigation, commercially brand "Rogor (EC 30\%)" has been purchased from the local supplier. The $\mathrm{LC}_{50}$ of Rogor fish was performed by the technique described in the standard methods (APHA, 2005), the 96h. LC $_{50}$ of Rogor for Clarias batrachus was calculated as $4 \mu$ l. The two doses considered in the experimental protocol were $1 \mu \mathrm{l} / \mathrm{L}$ and $2.5 \mu \mathrm{l} / \mathrm{L}$, accordingly stock solution of Rogor was prepared using distilled water. Fishes were then treated with $1.0 \mu \mathrm{l} / \mathrm{L}$ (lower) and $2.5 \mu \mathrm{l} / \mathrm{L}$ (upper sub lethal) for 15 days. The control group was maintained in the tap water only. The water and pesticide solution were changed regularly.

\section{Sample Collection}

On the termination of exposure period of 5 , 10 and 15 days blood sample of both control and experimental group were collected in a heparinized glass culture tube eppendorf by sterile syringe from caudal vein. The serum was separated by centrifuging blood at 5000 rev. $/ \mathrm{min}$ for $10 \mathrm{~min}$ at $4^{\circ} \mathrm{C}$ and stored at $-20^{\circ} \mathrm{C}$ for further hormone assessment. Fishes were anaesthetized with MS222 and the ovarian tissues were carefully removed and fixed for light and electron microscopy in the neutral formalin and $2.5 \%$ glutaraldehyde in $0.1 \mathrm{M}$ Phosphate buffer $(\mathrm{pH} 7.4)$ at $4^{\circ} \mathrm{C}$. The tissues were processed for Light Microscopy in laboratory as per routine method, finally stained with Haematoxylene and Eosin and viewed under Trinocoular Microscope, Labomed CXRIII. For Scanning Electron Microscopy ovarian tissues were washed in $0.1 \mathrm{M}$ phosphate buffer, dehydrated in graded series of alcohol and then in a mixer of absolute alcohol and amyl acetate $(1: 3,1: 1$ and $3: 1)$ and lastly in the pure amyl acetate. These dehydrated tissues were further dehydrated to critical point drawing in a critical point drier and Gold sputtered by gold coating machine and then viewed under Scanning Electron Microscope at SIF-EM Facility Unit Department of Anatomy New Delhi. Details of histopathological observations based on Light Microscopy (LM) as well as Electron Microscopy were depicted in Figures 4-7

\section{Hormone Assessment}

The hormone assessment of TSH FSH and Vitellogeninwere done on Merck 'mini mios' ELISA reader, as per standard protocol of WHO (2002). All the hormone assessment was done for control and treated fish C. batrachus. TSH assay was done by Micro plate immune enzymometric Assay. The kit was procured from Omega Technique Chemical Incorporation. TSH is a solid phase sandwich ELISA method. The samples and Biotin labelled anti-TSH-HRP conjugate are added to the wells coated with streptavidin TSH in the serum binds to anti$\mathrm{TSH}$ and form a sandwich with streptavidin coated wells. Unbound proteins are washed off by wash buffer. Upon the addition of the substrate, the intensity of colour is proportional to the concentration of TSH in the samples. The absorbance was measured at $450 \mathrm{~nm}$ against blank. FSH was done through Micro well FSH 
EIA techniques. The kit was procured from Syntron Bioresearch Incorporation. The Micro well FSHEIA is a solid-phase enzyme immunoassay based on the "Sandwich" principle. The FSH present in the test sample reacts simultaneously with one antibody immobilized on the micro well surface and with another antibody conjugated to horse radish peroxide enzyme. So an $\mathrm{Ab}-\mathrm{Ag}$ Ab-Enzyme complex was formed on the micro well surface. Then the unbound conjugate was removed by washing and the colour was changed upon exposure to the enzyme. The intensity of the colour is proportional to the FSH in the sample. The absorbances were measured at $450 \mathrm{~nm}$ against blank. The comp vitellogenin ELISA kit were purchased from Bioscience Laboratory, Norway. The lyophilized coup vitellogenin standard was calibrated against purified cat fish vitellogenin. And vitellogenin concentration $(\mathrm{mg} / \mathrm{mg}=$ absorbance at 286 $\mathrm{nm} / 0.66$, range $=0.24 \mathrm{ng} / \mathrm{ml}$.) were measured. For each blood serum TSH and FSH and Vitellogenin assay, six observations were taken. The arithmetic mean was calculated and subjected to statistical analysis. The evaluation of each parameter was performed by its mean \pm SD. The obtained data were subjected to paired test. Values at $P<0.05, P<0.01$ and $P<0.001$ were considered to be significant. All statistical analysis were done using Sigma Plot 8.0 version. The results obtained have been included in tabular form, pictorial statistical representation and graphical plates of the present work. A parallel comparison was undertaken between the serum TSH, FSH and vitellogenin level of control fish with the Rogor treated group, likewise, LM and SEM photomicrograph of ovarian tissue of Rogor treated fish were compared with control fish.

\section{Results and Discussion}

On perusal of the Fig. 1 Fluctuation of Thyroid Stimulating Hormone (TSH) level increased $(2.8 \pm 0.141 \mu \mathrm{IU})$ after 5 days exposure of Rogor $(1 \mu \mathrm{l} / \mathrm{L})$ whereas on 10 th day it abruptly decreased $(0.2 \pm 0.089 \mu \mathrm{IU})$ and then increased $(2.8 \pm 0.141 \mu \mathrm{lU})$ after 15 days as compared to normal $(2.255 \pm 0.187 \mu \mathrm{IU})$ level. Comparatively, by giving the high dose of $2.5 \mu \mathrm{l} / \mathrm{L}$ TSH level increased abruptly $(3.45 \pm 0.104 \mu \mathrm{lU})$ after 5 days and then after 10 days it decreased $(0.583$ $\pm 0.147 \mu \mathrm{IU}$ ) but decreased less than the former dose. After 15 days it increased sharply (2.033 $\pm 0.186 \mu \mathrm{lU}$ ) but did not reach to normal level. Fig. 2 represents follicle stimulating hormone

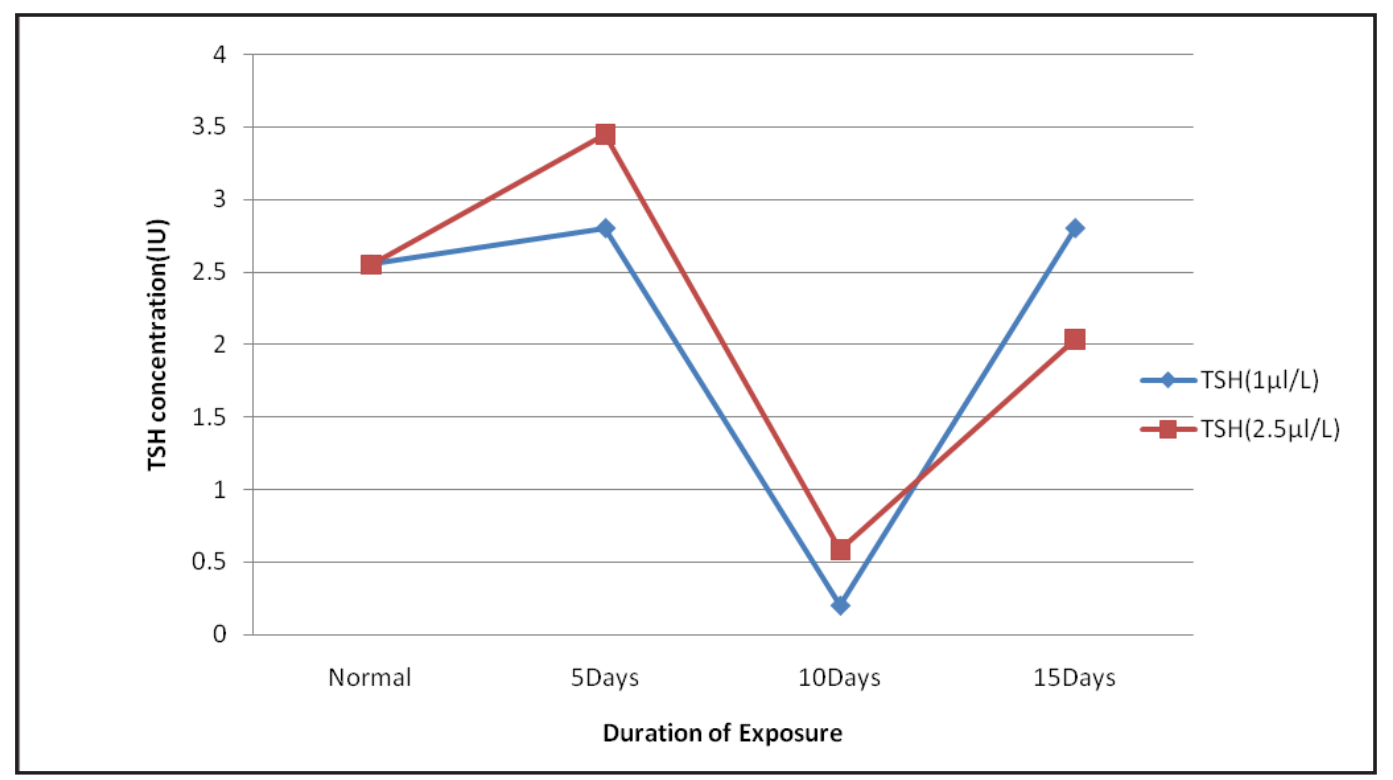

Fig. 1 Fluctuation of serum TSH level in control and Rogor treated Clarias batrachus (Linn.), $(n=6)$. 
(FSH) which was slightly decreased $(132.3 \pm$ $0.554 \mu \mathrm{IU}$ ) after 5 days of treatment of Rogor in both dose $(1 \mu \mathrm{l} / \mathrm{L}$ and2.5 $\mu \mathrm{l} / \mathrm{L})$ in comparison to normal level. Whereas after 10 day it slightly increased $(137.383 \pm 0.147 \mu \mathrm{lU})$ by the dose of $1 \mu \mathrm{l} / \mathrm{L}$ and abruptly shoots up (54.167 \pm $3.017 \mu \mathrm{IU})$ at the dose of $2.5 \mu \mathrm{l} / \mathrm{L}$. After 15 days exposure of $1 \mu \mathrm{l} / \mathrm{L}$ Rogor the $\mathrm{FSH}$ level sharply increased $(181.883 \pm 0.479 \mu \mathrm{IU})$ but it abruptly decreased (137.133 $\pm 0.484 \mu \mathrm{lU})$ after giving $2.5 \mu \mathrm{l} / \mathrm{L}$ Rogor. Figure 3 represents, serum Vitellogenin level which slightly decreased from $(2.20 \pm 0.554 \mathrm{IU})$ to $(1.10 \pm$ 0.2 ) after five days of Rogor treatment in both dose $(1 \mu \mathrm{l} / \mathrm{L} ; 2.5 \mu \mathrm{l} / \mathrm{L})$ respectively as compared to normal $(2.24 \pm 3.31)$. However, on tenth day it sharply increased $(2.82 \pm 0.62)$ and $(2.86 \pm$ 2.94) respectively but after 15 days it fell down abruptly up to minimum level, which was difficult to estimate. The abnormal fluctuation of serum TSH, FSH and Vitellogenin level can be further correlated with the histopathological observations. Histopathological observations of ovarian tissue from control fish showed different stages of the oocytes in the ovigerous lamellae which extended from well developed germinal epithelium along with a few interstitial nutritive cells. Nucleus and Nucleolus are distinct (Fig. 4.1.). However, $1 \mu \mathrm{l} / \mathrm{L}$ Rogor treated for 5 Days, ovarian tissue revealed ruptured ovigerous lamellae, fusion of a number of young and maturing oocyte, shrinkage of nucleus and peripheral vacuolization (Fig. 4.2). After 10 day ovarian tissue showed extensive degeneration of the ovigerous lamellae and increased fusion of oocytes, The plasma membrane and theca cell get ruptured and shrinkage of nuclear material were increased. (Fig. 4.3). After 15 day almost

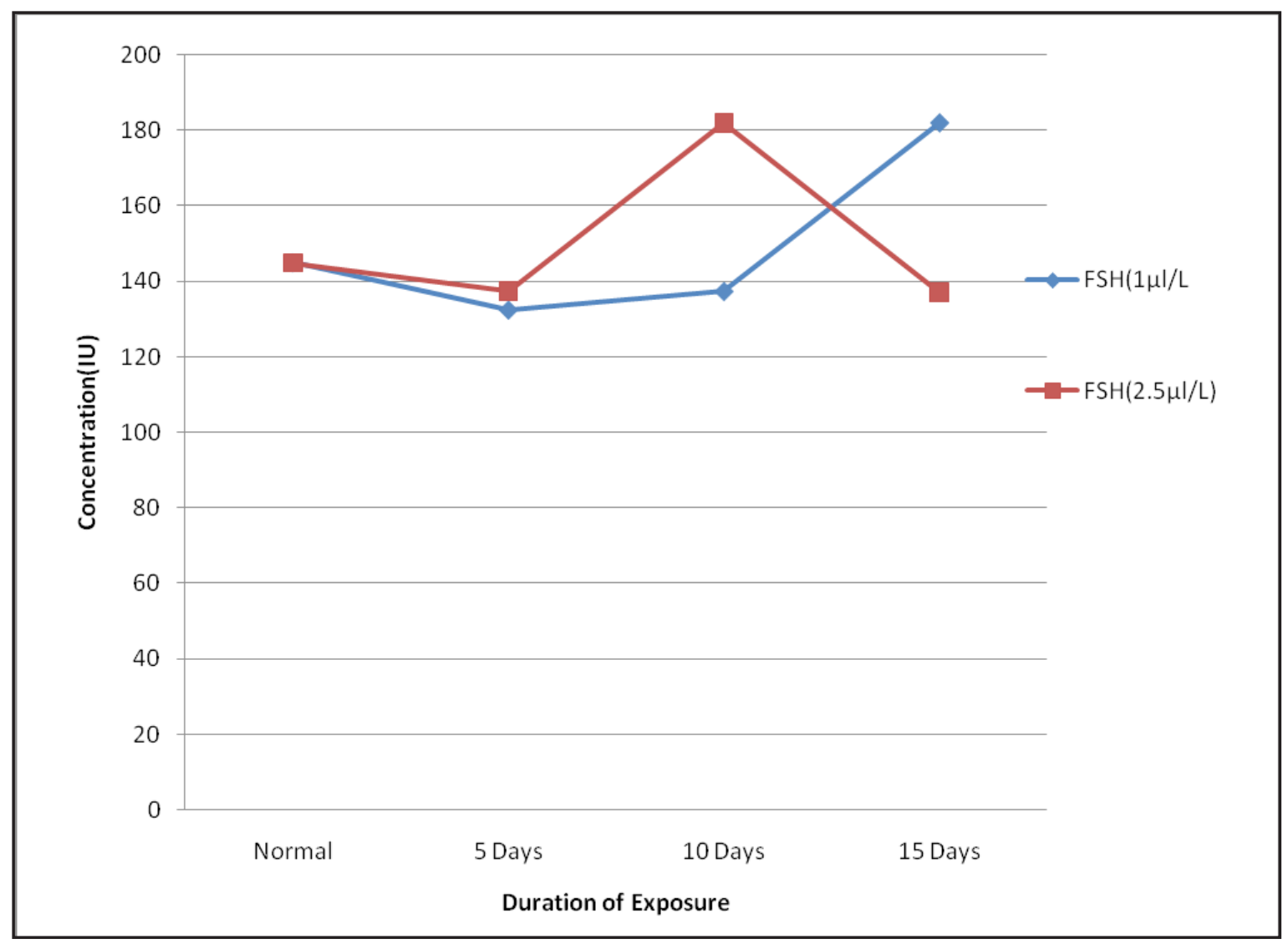

Fig. 2 Fluctuation of serum FSH level in control and Rogor treated Clarias batrachus (Linn.), $(n=6)$. 


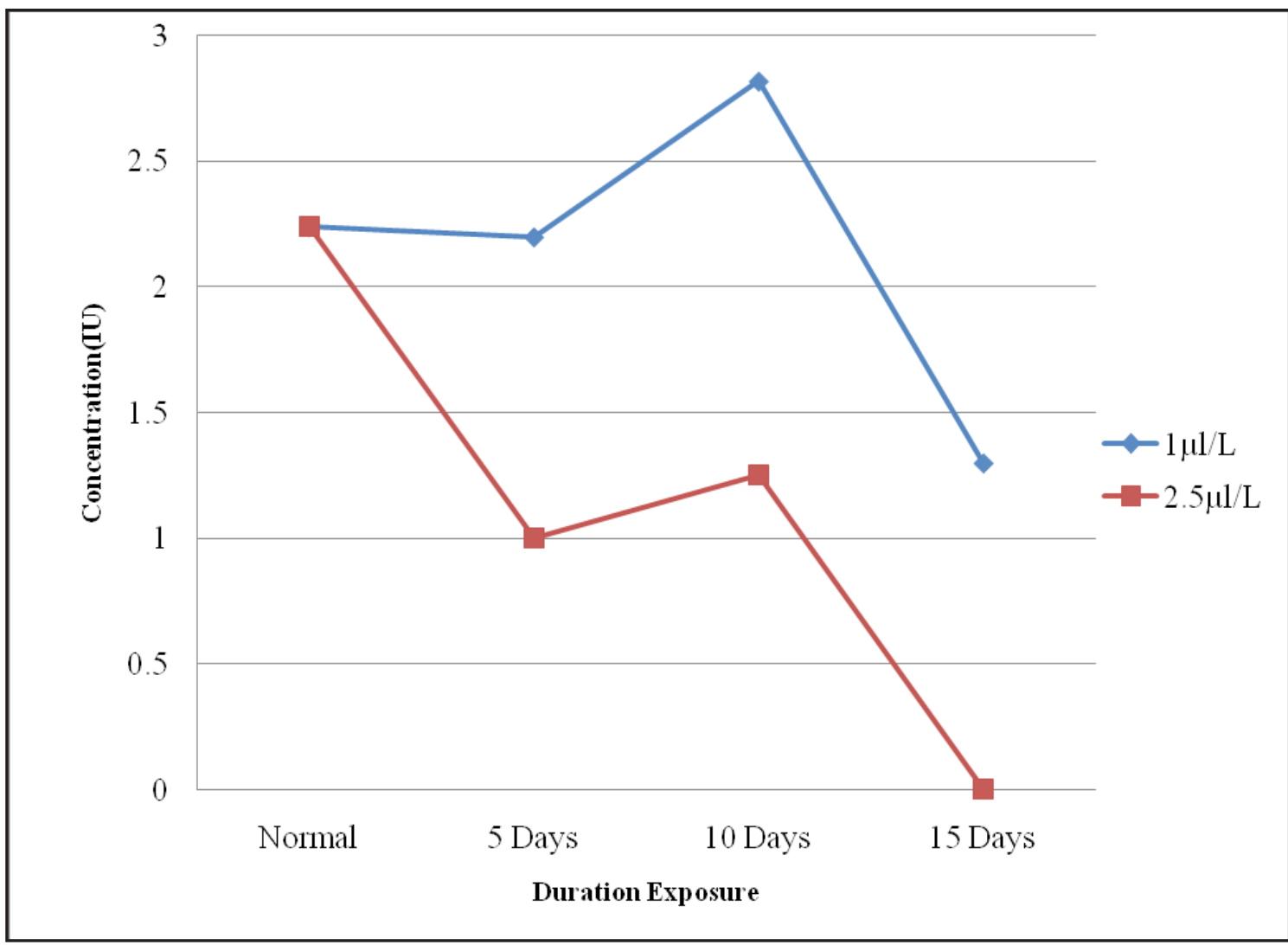

Fig. 3 Fluctuation of serum Cortisol level in control and Rogor treated Clarias batrachus (Linn.), $(n=6)$.

all oocyte showed fusion, massive vacuolation, shrinkage of nuclear material and atretic follicle (Fig. 4.4). 2.5 $\mathrm{\mu l} / \mathrm{L}$ Rogor exposure for 5 days oocyte show ruptured germinal epithelium and ovigerous lamella. Most of the oocyte of stage 1, 2 and 3 undergoes atresia. Preivitellogenic and vitellogenic oocyte showed shrinkage of nuclear material leaving peripheral vacuolation (Fig. 5.1). After 10 Day the most striking feature was that all stages of oocyte undergoes atresia. The worst affected oocyte was stage $S_{1}$ to $S_{4}$ (Fig. 5.2), after 15 days oocyte showed complete acellularity along with absence of nuclear material (Fig. 5.3 and 5.4).

Scanning Electron Microphotograph of the ovarian tissue of control Clarias batrachus showed three dimensional surface morphology of ova, smooth, rounded surface with surface epithelium attached to it. Interdigitate blebs (microvilli) were also seen on the surface along with some electron dense macro granules scattered over the oocyte surface (Fig. 6.1). $1 \mu \mathrm{l} / \mathrm{L}$ Rogor, 5 days treated C. batrachus ovarian tissue showed a number of depression, striations and wavy appearance of the ova with scattered macro granules (Fig. 6.2). After 10 days showing prominent tetra and hexagonal veins, protuberances and sign of rupturing of ova (Fig. 6.3) which increases after 15 days (Fig. 6.4). However, $2.5 \mu \mathrm{l} / \mathrm{L}$ Rogor 5 days treated fish ovarian tissue showed grooves and depression (Fig.7.1). After 10 days follicular epithelium showed loosened and ruptured surface epithelium (Fig. 7.2). Superficial and deep furrow increased after 15 days with prominent raised portion showing acellularity (Fig. 7.3). 

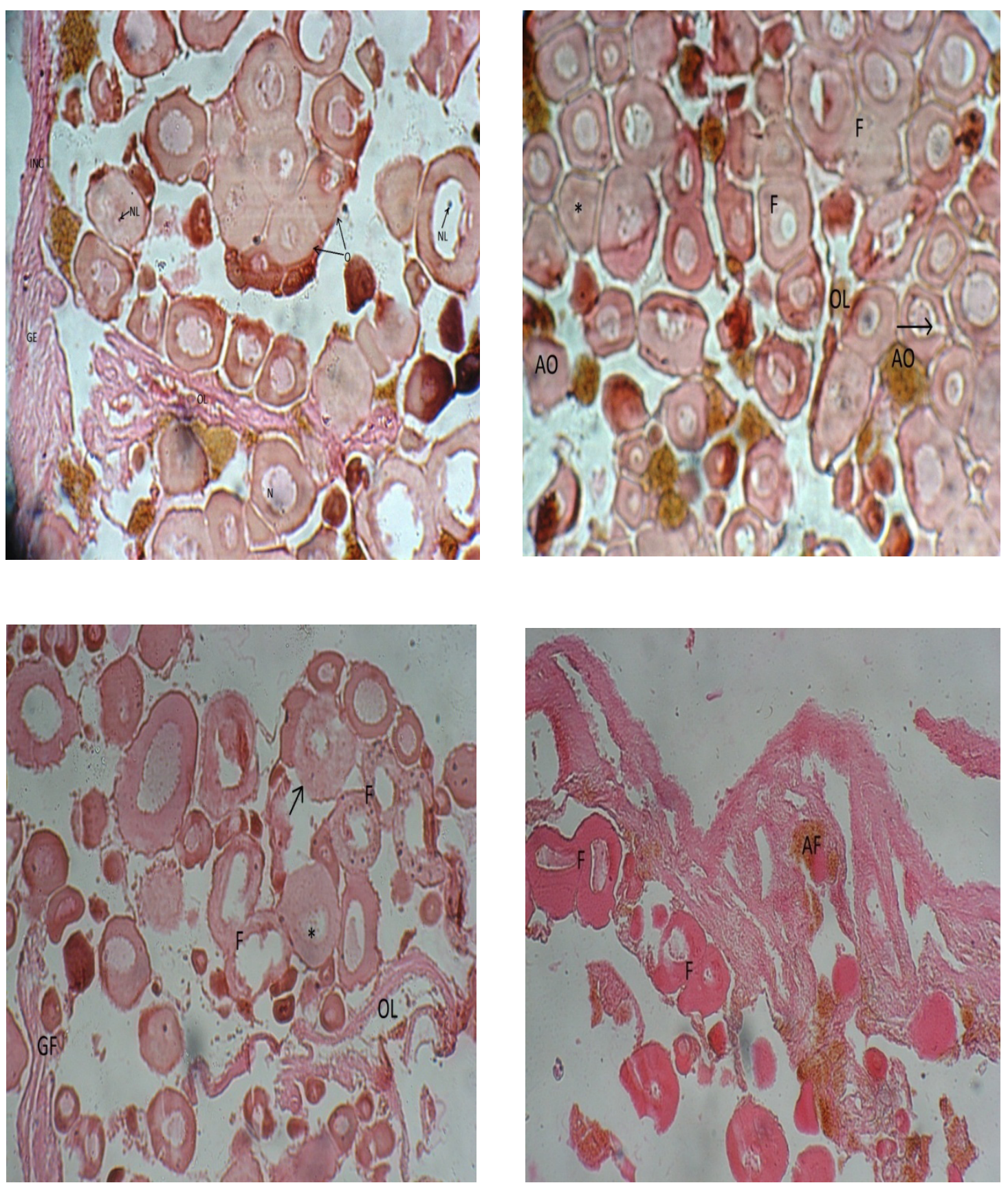

Fig. 4 Photomicrograph of transverse section of Ovary of $C$. batrachus stained with haematoxylene and eosin.

1. Control fish ovary showing different stages of the oocytes in the ovigerous lamellae $(\mathrm{OL})$ extended well developed germinal epithelium (GE) nucleus (N) are distinct. Note few interstitial nutritive cells (INC) along GE. X 200

2. Section of ovary treated with $1 \mu \mathrm{l} / \mathrm{L}$ Rogor for 5 days, showing ruptured ovigerous lamellae, a no. of young and maturing oocyte fusion, shrinkage of nucleus and peripheral vacuolization and increased atretic oocyte. $(\rightarrow)$. X 200

3. After 10 days showing extensive OL and increased fusion of different stages of oocyte, Note increased atresia of oocyte, increased shrinkage of nuclear material. X 200

4. After 15 days of exposure showing extensive degeneration almost all oocyte showing fusion, extensive shrinkage of nuclear material and atretic follicle. X 400 

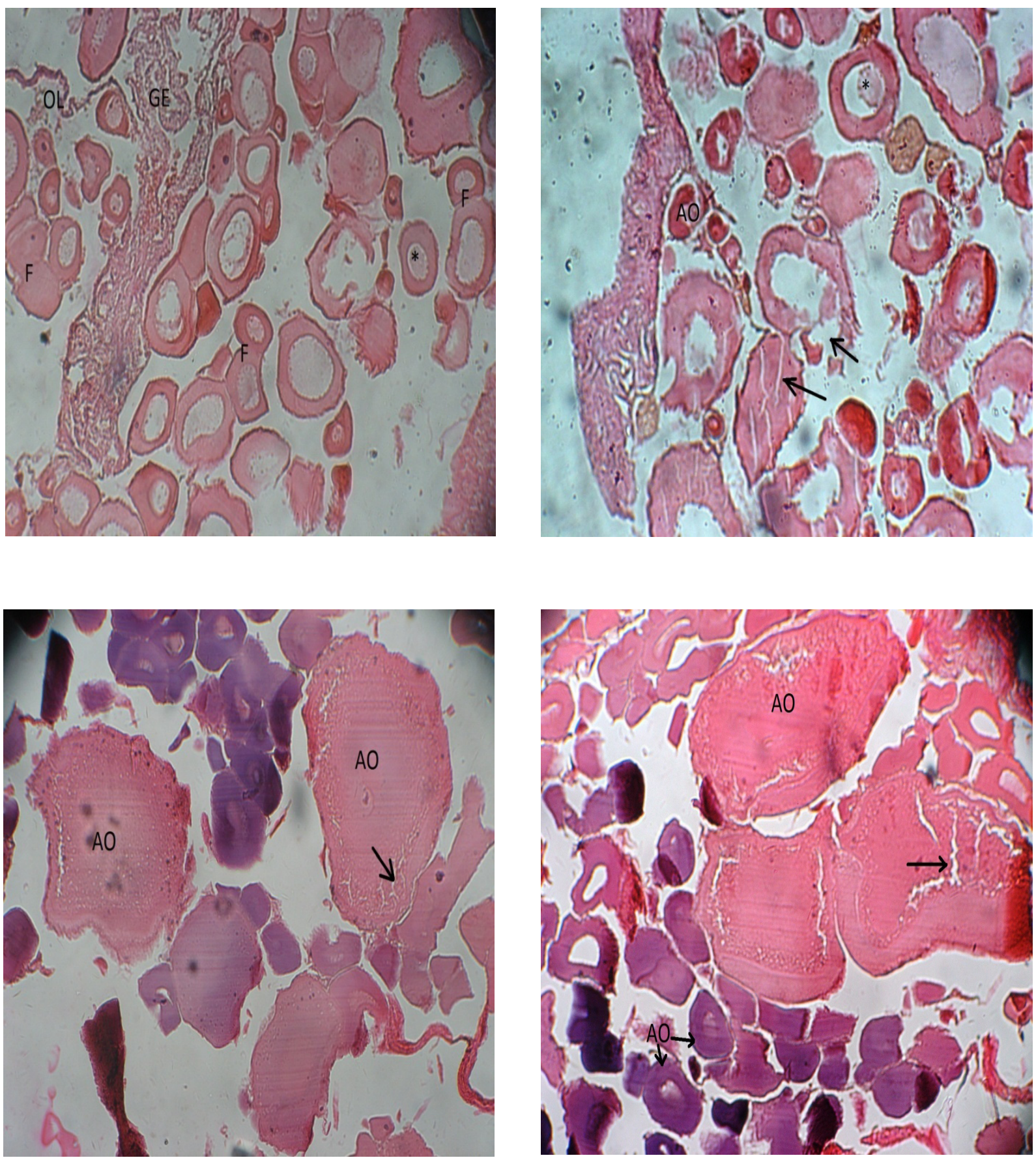

Fig. 5 Photomicrograph of transverse section of Ovary of $C$. batrachus stained with haematoxylene and eosin.

1. Oocytes after 5 days, rogor exposure showing ruptured GE and OL and shrinkage of nuclear materials leaving peripheral vacuolation. Note the increased fusion of oocyte of stage I, II and III. X 400

2. After 10 days rogor exposure, all stages of oocyte undergoes atresia, the worst affected is stage I to IV oocyte. $X 200$

3. and 4. After 15 days exposure showing complete deformity in the oocyte along with complete absence of nuclear material, showing acellularity. Note the extensive cracking following complete atresia. $X 400$ 

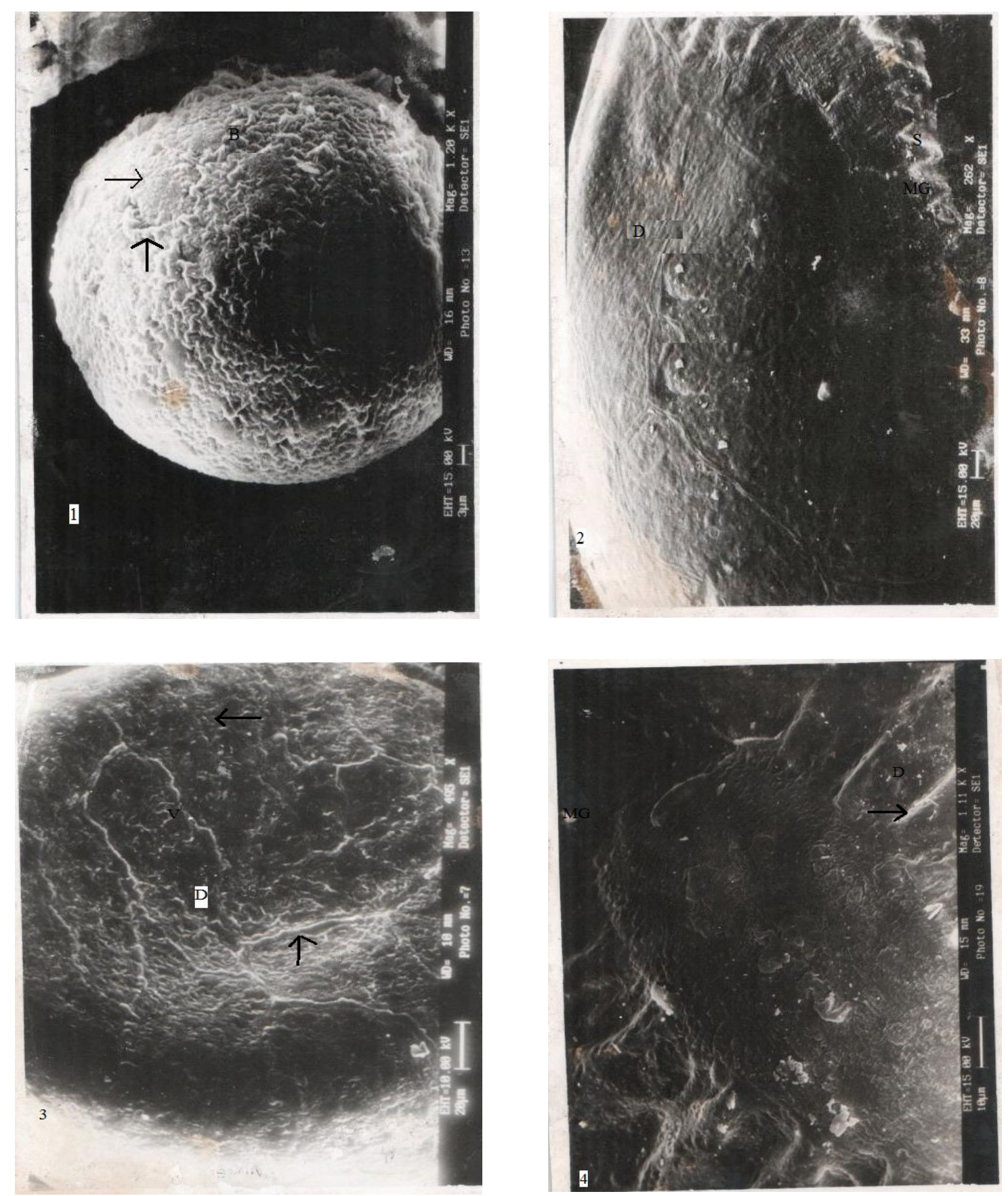

Fig. 6 Scanning Electron Microphotograph of the ovary of Clarias batrachus.

1. Scanning Electron Microphotograph of the ovary of control Clarias batrachus showing oocyte with normal, smooth, rounded surface $(\rightarrow)$ with surface epithelium attached to it $(\uparrow)$. Note- the interdigitate blebs (B).

2. Oocyte of $1 \mu \mathrm{l} / \mathrm{L}$ rogor, 5 days treated $C$. batrachus showing a number of depression $(\mathrm{V})$, striations and wavy appearance (S) of the oocyte with scattered macrogranules (MG).

3. After 10 days ova showing prominent tetra and hexagonal veins $(\vee)$, protuberances $(\uparrow)$ and sign of rupturing of ova $(\leftarrow)$.

4. After 15 days showing a number of depressions (D), striations and wavy appearance(S) of the oocyte surface with scattered macrogranules (MG), ruptured ova with oozing the cytoplasmic inclusions out of the ova $(\rightarrow)$. 

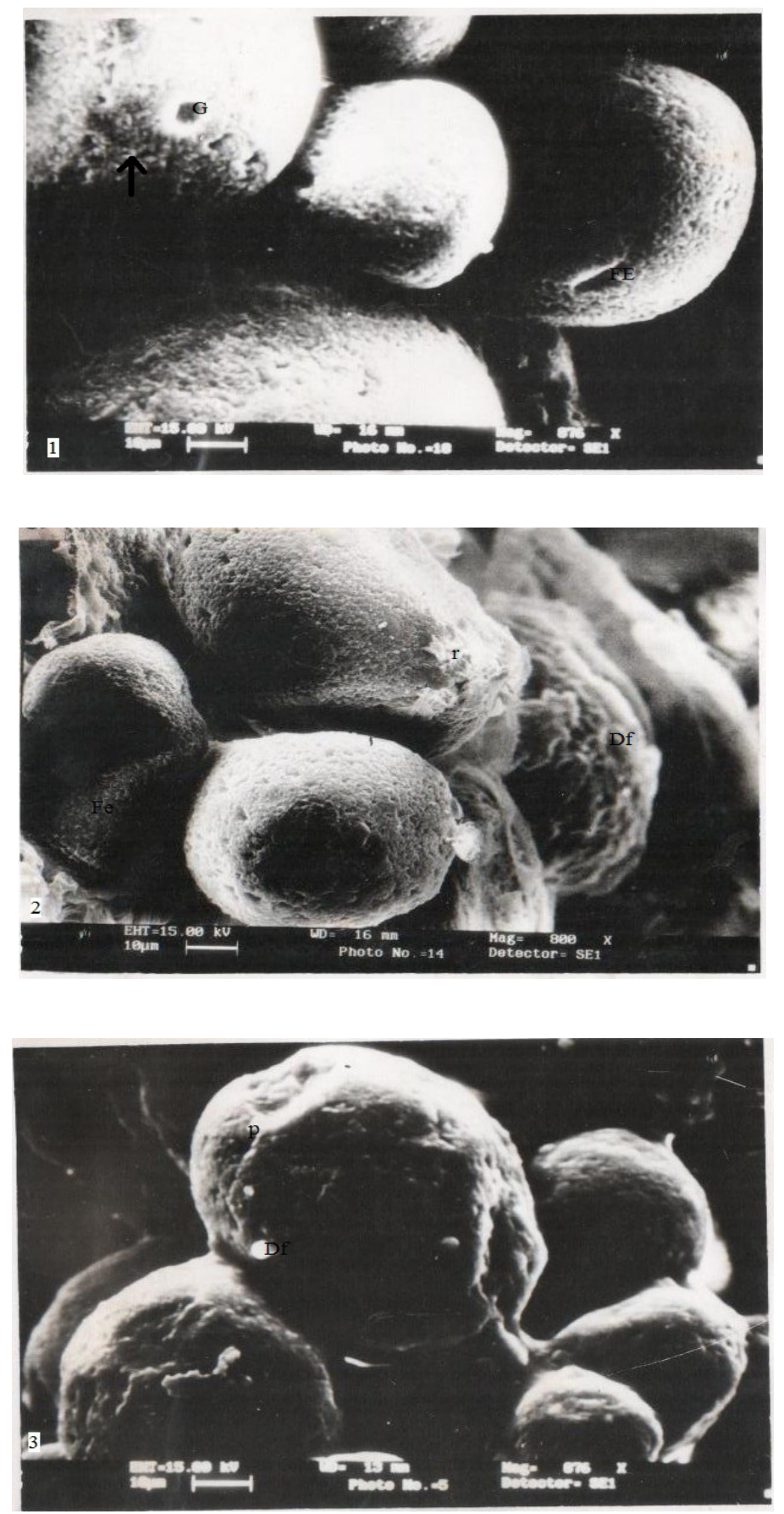

Fig.7 Rogor treated fish ovary

1. $2.5 \mu \mathrm{l} / \mathrm{L}$ of Rogor 5 days treated fish ovary showing grooves $(G)$ and more depression and follicular epithelium (FE) with shriveled surface. Magnified portion deep groove $(G)$ on the oocyte surface. Bulbous protrusion also seen adhering the oocyte surface $(\uparrow)$.

2. Portion of the ovary of rogor treated $\mathrm{C}$. batrachus (10 Days). Follicular epithelium (Fe) loosened and ruptured. Superficial ( $r$ ) and deep furrow (Df) observed.

3. Protuberances $(p)$ prominent. Inter oocyte with a prominent raised portion, the protuberance (p). Oocytes with more deeper and wider furrow (Df). 
The present investigation in lights the Rogor exposure causes sharp fluctuation of various hormones and several structural deformities and abnormalities in the ovary of Clarias batrachus, at subcellular level.Pesticides have been found to enhance the incidence of follicular atresia depending upon the period of exposure under laboratory conditions. Rogor causes extensive damage to developing oocytes only after fifth day of the exposure followed by tenth and fifteenth day. The result has convincingly favoured by Mani and Saxena (1985) who studied the effect of sub lethal concentration of fenitrothion and carbofuran on the oocyte of Channapunctatus causing more atretic oocyte. In the present investigation cytoplasm clumping was observed which is in consistency with Saxena and Garg (1978). The dissolution of the ooplasmic contents and hence, vacuolation was observed in the cytoplasm of the oocytes of all the growing six stages (Singh and Sahai,1986) which probably interferes in the movement of yolk precursors thereby, inhibiting vitellogenesis. Literatures is available supporting suchim balances inserum hormones and ultrastrctural changes due to pesticides on fish ovary (Deka et al., 2012; Verma et al, 2004). These include clumping of cytoplasm, vacuolations and shrinkage in nuclear material in vitellogenic oocytes. Tripathy and Verma (1993) and others have also reported that histomorphology of the teleostean ovary vis-a vis maturation of oocytes is adversely affected by different biocides as observed presently in Clarias batrachus after Rogor exposure. Guraya (1979) considered destruction of yolk nucleus as one of the possible causative factors for oocyte atresia as the former is reportedly involved in active RNAProtein synthesis prior to vitellogenesis. Similar result has also been observed that thickening of ovarian wall, basement membrane and atretic follicle increases with dose and duration of both $1 \mu \mathrm{i} / \mathrm{L}$ and $2.5 \mu \mathrm{l} / \mathrm{l}$ Rogor exposure. The treated fish reveals interdigitate furrow and polygonal striation on the surface of the oocyte which becomes more apparent with prolonged exposure in both doses under scanning elec- tron microscope. Probably, disorganisation of this network contributes for the follicular deformity. Alterations in the cell surface reflects hormonal imbalance or other substances that interact with the cell (Flickinger, 1979). Teleost thyroid is associated with many physiological and environmental changes. It has been found to be involved in affecting growth reproduction, osmoregulation and energy metabolism (Turner, 1966; Matty, 1985). Increased serum TSH level and simultaneously decrease in the serum FSH level after fifth day treatment of Rogor coincides with the report of Hulburt (1977), who showed that the thyroid hormone act synergistically with gonadotropin. Similarly, high level of serum TSH and diminished level of serum vitellogenin after fifteen days of Rogor exposure is in corroboration with histological findings. Thus sub lethal dose of Rogor may be presumed to effect the oocyte directly disrupting normal function of the yolk nucleus by binding to mitochondrial protein and thereby, interfering energy production in the young oocyte of the present fish C. batrachus. Since the secretion of TSH is negative feedback (Turner, 1966) so its concentration sharply decreases after ten day Rogor treatment in both doses whereas serum FSH level slightly shoots up after ten day in the present findings. It can be correlated with the findings of Singh and Singh (1980) who expressed that pesticide cause low level of serum and blood gonadotropin in fish due to accumulation or direct toxic action on the ovary. It can be correlated with the increase in the follicular atresia after fifteen day of Rogor exposure due to decreased level of serum FSH level. Parallel to this finding Christians and Williams (2002) also suggested that FSH may play a role in egg size number trade off in oviparous vertebrates. Increase in serum vitellognin level and further decrease in fifteen day of Rogor exposure suggested that the pesticide can act as positive or negative modulator of vitellogenin. The results is in corroboration with the findings of Okoumassoun et al. (2002), who have shown the estrogenic potential of organochlorine as positive and 
negative modulator. Massive damage of vitellogenin oocyte under light and scanning electron microscope after $2.51 \mu \mathrm{l} / \mathrm{L}$ Rogor exposure for 15 days is in consistency with the abruptly decreased level of serum vitellogenin level after similar treatment of Rogor. Fujita et al (2004) have quantified serum vitellogenin level as precursor to vitelline envelop proteins and vitellogenin in estrogen treated maso salmon $O$. masou. Prakash et al. (2007) have established ELISA for mural vitellogenin and chloriogenin as biomarker of potential endocrine disruptor. Increased atrophy of stage I-V oocytes occurs after 1 and $2.5 \mu \mathrm{l} / \mathrm{L}$. Rogor exposure during all the experimental period probably due to the abnormal increased and decreased level of serum FSH in both the doses.

The present communications are in conclusion with detailed discussion that roger produces profound impact on the growth and maturation of oocytes in C. batrachus. Specially massive degeneration and atrophy of stage $\mathrm{I}-\mathrm{V}$ oocytes. Thyroid has been reported to take active participation in growth processes in fish. Fish pituitary contains variable amount of TSH and FSH which causes involvement in growth, reproduction and other metabolic activities. The combined histopathological and hormonal imbalance will affect the process of oogenesis in fish. Specially vitellogenesis of the mature oocytes. The oocyte degeneration reflects a variety of pathological condition andultimately causes death. The increased Serum TSH and decreased $\mathrm{FSH}$ and vitellogenin level also reveals the extreme pathological condition which also serves as a good indicator of fish reproductive health.

\section{Acknowledgement}

Authors are thankful to Women Scientist Scheme, SERC Division, Department of Science andTechnology, New Delhi for providing fund (Project No. DSTNo:SR/ WOS-A/LS-17/2008), Vice-Chancellor, Patna University andDepartment of Zoology, Patna University for providing research facility, along with members of EM Facility Unit, Department of Anatomy AlIMS, New Delhi for kind cooperation for SEM.

\section{References}

APHA (2005) Standard method for the examination of water and wastewater $\left(21^{\text {st }} \mathrm{Ed}\right) \mathrm{A}$ joint publication of the American Public Health Association (APHA), the American Water Works Association (AWWA), and the water environment Federation (WEF), 1368.

Christians, J.K. and Williams, T.D. (2002) Effects of porcine follicle-stimulating hormone on the reproductive performance of female zebrafinches. Gen Comp. Endocrinol., 125, 260-267

Deka, S and Mahanta, R. (2012) A Study on the Effect of Organophosphorous Pesticide Malathion on Hepato, Renal and Reproductive Organs of Heteropneustesfossilis (Bloch). Sci. Probe., 1, 1-13

Dubois, K..P. (1971) The Toxicity oforganophosphorous compounds to mammals.Bull. Wld..HIth. Org., 44, 233-240

Dutta, H. M. et al. (1994) Sublethalmalathion induced changes in the ovary of an air breathing fish $\mathrm{H}$. fossils: A histologocal study. Hydribiologia., 29, 216-218.

Flickiinger, C.J., Brown, J.C., Kutchi, H.C. and Ogilvie (1979) Medical Cell. Biol., Hoft Savnders. Philadlphia

Fujita, T., Fukada, H., Shimizu, M., Hiramatsu, N. and Hara, A. (2004) Quantification of serum levels of precursors to vitelline envelope proteins (choriogenins) and vitellogenin in estrogen treated masu salmon, Oncorhynchusmasou. Gen Comp Endocrinol., 136, 2004, 49-57.

Guraya, S.S. (1977) Recent advances in morphology, histochemistry and biochemistry of steroid synthesis cellular sites in non-mammalian vertibrates ovary. Int. Rev. Cytol., 44, 365-409.

Hurlburt, M.E. (1977) Role of thyroid gland in ovarian maturation of gold fish, Carassiusauratus L. Can. J. Zool., 55, 1906-1913.

Kobayashi T., Fushiki S., Sakat N.P., Hara, A. and Amano, M. AIDA (1998) Oogenesis and changes in the level of reproductive hormone in triloid female rainbow trout. Fish. Sci. (Tokyo)., 64, 206-215.

Mani, K and Saxena, P.K. (1985) Effect of safe concentrations of some pesticides in ovarian recrudescence in the fresh water murrel Channapunctatus. A quantitative study. Ecotoxicol. Environ. Safety, 9, 241-249. 
Matty, A.J. (1985) Fish endocrinology "Cicom Helm London and Sydney Timber Press Portland" Qregon-P-267.

Monteverdi, G.H., Giulio and Di, R.T. (2000) Vitellogenin association of thyroxine and 3,5,3-triiodothyronine in gravid Fundulusheteroclitus. Gen. Comp. Endocrinol., 120, 198-121.

Nath, A. (2003) Serum hormonal imbalance and altered reproductive physiology in fish due to aquatic ecotoxicity: A. preventive approach. J. Ecophysiol. Occup. Hith., 3, 37-50.

Nath, P and Maitra, S. (2001) Role of two plasma vitellogenin from Indian major carp Cirrhnusmrigala and catfish Clarias batrachus vitellogenesis. Gen. Comp. Endrinol., 124, 30-44.

Okoumassoun, L.E. et al. (2002) Assessing the estrogenic potential of organochlorine pesticide in primary cultures of male rainbow trout (Oncorhynchusmykiss) hepatocytes using Vitelloganin as a biomarker. Toxicol., 178,193-207.

Okumura, T., Yoshida, K. and Nikaido, H. (2004) Ovarian development and hemolymphvitellogenin levels in laboratory- maintained protandricshrip, Pandalushypsinotus: measurement by a newly developed time- resolved fluoroimmunoassay (TR-FIA). Zoological Sci., 21, 1037-1047.

Ramachandra, Mohan M. (2000) Malathion induced changes in the ovary of fresh water fish. Gliossogobiusgluris. Poll. Res., 19, 73-75.

Saxena, P.K. and Garg, M. (1978) Effect of insecticidal pollution on ovarian recrudescence in a fresh water teleost Channapunctatus. Ind. J. Exp. Biol., 16, 690-691.

Singh, S. and Sahai, S. (1986) Toxic effects of BHC on the immature ovary of Rasboradaniconius (Ham.). Proc Nat. Acad. Sci., India., 56, 106-110.
Singh, H. and Singh, T.P. (1980) Effect of 2 pesticides on total lipid and cholesterol content of ovary,liver and blood serum during different phases of the animal reproductive cycle in the fresh water teleost $\mathrm{H}$ fossilis. Environ. Pollut. Ser-A Eco. Biol., 23, 8-18

Tripathy, S. and Verma, G.P. (1993) Effect of sumicidin on vitellogenesis in the a fresh water teleost, Tilapia mossambica (Peters). In Environmental impact on Aquatic and Terrestrial Habitats. (Eds: Agrawal VP, Abidi SAH and Verma GP), pp. 79-94. Society of biosciences, Mujaffar Nagar, India.

Turner C.D. (1966) 'General Endocrinology'. $4^{\text {th }}$ Edition, W.B. Saunders Company, Philadelphia, London.

Ura, K, Hiramatsu, N., Amano, H., Fujita, T., Matsubara, T, Sullivan, C.V., Soyano, K. and Hara, A. (2006) Fish Vitellogenin: Application as a biomarker protein. Aquat. Toxicol.,

Verma, P., Kedia, K.D. and Nath, A. (2004) Carbofuran induced ultrastructural changes in the ovary of Clarias batrachus. Perspect. Cytol. Genet., XI, 397-401

Verma, P and Nath A. (2003) Electron Microscopic Structure of Ovarian Follicle of Clarias batrachus after Rogor treatment. Proc. Zool. Soc., India. 2, 7-12

Verma, P. and Rani, P. (2013) Pesticide accumulation, alteration of serum vitellogenin, and TSH level and occurrence in air breathing fish Clarias batrachus (Linn.). Patna University,

Zagatto, P. A. (1999) "Mini-curso: ecotoxicologia aquática". VII Congresso Brasileiro de Limnologia. Florianópolis: SBL, 124p. 